\title{
UTILIZAÇÃO DE SISTEMAS FOTOTÉRMICOS COM CONCENTRADORES PARA HIGIENIZAÇÃO DE SALAS DE ORDENHA
}

\section{LEANDRA ALTOE ${ }^{1}$, DELLY OLIVEIRA FILHO ${ }^{2}$}

\begin{abstract}
RESUMO: Neste trabalho, analisou-se a viabilidade do uso de concentradores de radiação solar em sistemas fototérmicos para higienização de salas de ordenha. Foram analisadas três opções para aquecimento de água com reservatório de acumulação: sistema com resistência elétrica, sistema solar com concentrador e sistema solar sem concentrador. Calculou-se o custo total dessas alternativas e o valor presente líquido do sistema solar suplementado por lenha de eucalipto comprada, lenha de eucalipto produzida na propriedade rural, energia elétrica e gás liquefeito de petróleo (GLP). Realizou-se uma análise de sensibilidade do sistema fototérmico variando o número de vacas lactantes, o custo da energia elétrica e da lenha, a taxa de juros, o custo dos componentes do sistema, a vida útil e o subsídio no valor do equipamento. O sistema fototérmico com concentrador suplementado por lenha produzida na propriedade foi a alternativa de aquecimento mais viável economicamente. $\mathrm{O}$ uso dos concentradores gera uma redução de cerca de $10 \%$ no custo de aquisição do sistema de aquecimento solar.
\end{abstract}

PALAVRAS-CHAVE: energia solar, aquecimento de água, produção de leite.

\section{USE OF THE THERMAL SOLAR SYSTEMS WITH CONCENTRATORS FOR THE HYGIENE OF MILKING PARLOR}

\begin{abstract}
In this study, we analyzed the feasibility of using radiation concentrators in thermal solar systems for the hygiene of milking parlors. We analyzed three options for water heating with tank accumulation: system with electric resistance, the solar system with concentrator and the solar system without concentrator. It was calculated the total cost of these alternatives and the net present value of the solar system supplemented by purchased eucalyptus wood, eucalyptus wood produced on the farm, electricity and liquefied petroleum gas (LPG). A sensitivity analysis of the thermal solar system varying the number of dairy cows, the electricity and the firewood costs, the interest rate, the system's components cost, the life expectancy and the subsidy on the equipment value. The thermal solar system with concentrator supplemented by firewood produced on the property was the more feasible heating alternative. The use of concentrators caused a reduction of around $10 \%$ of the purchase cost of solar heating system.
\end{abstract}

KEYWORDS: solar energy, water heating, milk production.

\section{INTRODUÇÃO}

A energia solar é responsável pela origem de quase todas as formas de energia, como hidráulica, biomassa e combustíveis fósseis. A utilização direta da energia gerada pelo sol é uma alternativa promissora para enfrentar os desafios do novo milênio. Pois esta é ilimitada na escala terrestre de tempo, e seu aproveitamento não gera impactos ambientais negativos (OLIVEIRA et al., 2008). Uma questão relevante neste contexto é comparar o uso da energia solar, de forma técnica e econômica, com fontes de energia mais difundidas (MARINI \& ROSSI, 2005).

O aquecimento de água é uma das formas mais viáveis de aproveitamento da energia solar. No meio rural, destaca-se a utilização de água quente na cadeia produtiva do leite, a qual é utilizada para a higienização dos equipamentos de ordenha (SOUZA et al., 2005). Sendo que a bovinocultura

\footnotetext{
${ }^{1}$ Graduanda em Engenharia Agrícola e Ambiental, Departamento de Engenharia Agrícola, Universidade Federal de Viçosa - MG.

${ }^{2}$ Prof. Doutor, Departamento de Engenharia Agrícola, Universidade Federal de Viçosa - MG. 
leiteira ocupa posição de destaque no cenário agropecuária brasileiro, por seu elevado valor de produção (BOTEGA et al., 2008). E essa produção só não é maior devido a certas práticas adotadas pelos produtores, como baixa tecnificação e falta de controle sanitário (NERO et al., 2009).

Algumas medidas devem ser tomadas para a realização da ordenha, com o objetivo de melhorar a qualidade microbiológica do leite produzido. A ordenhadeira, as mãos do ordenhador, práticas de higiene e lesões nos tetos são fatores que expõem a superfície dos tetos aos microrganismos patogênicos, sendo que esses microrganismos são transmitidos de animais infectados para não infectados durante o processo de ordenha (AMARAL et al., 2004).

Para garantir a qualidade do leite, a legislação brasileira referente à produção leiteira foi alterada pelo Ministério da Agricultura, Pecuária e Abastecimento (MAPA) em 2002. O Programa Nacional de Melhoria da Qualidade do Leite passou por alterações e transformou-se na Instrução Normativa $\mathrm{n}^{\mathrm{o}} 51$, que estabelece normas para produção leiteira, como quantidade de água quente necessária por animal de acordo com o tipo de leite produzido (GUERREIRO et al., 2005).

Os sistemas fototérmicos mais difundidos são compostos por coletores solares planos e reservatório térmico. O movimenta da água no sistema ocorre por diferença de densidade. A água fria, sendo mais pesada, impulsiona a água quente, que é mais leve, realizando a circulação (DAMASIO \& STEFFANI, 2007). Um sistema solar térmico é mostrado na Figura 1.

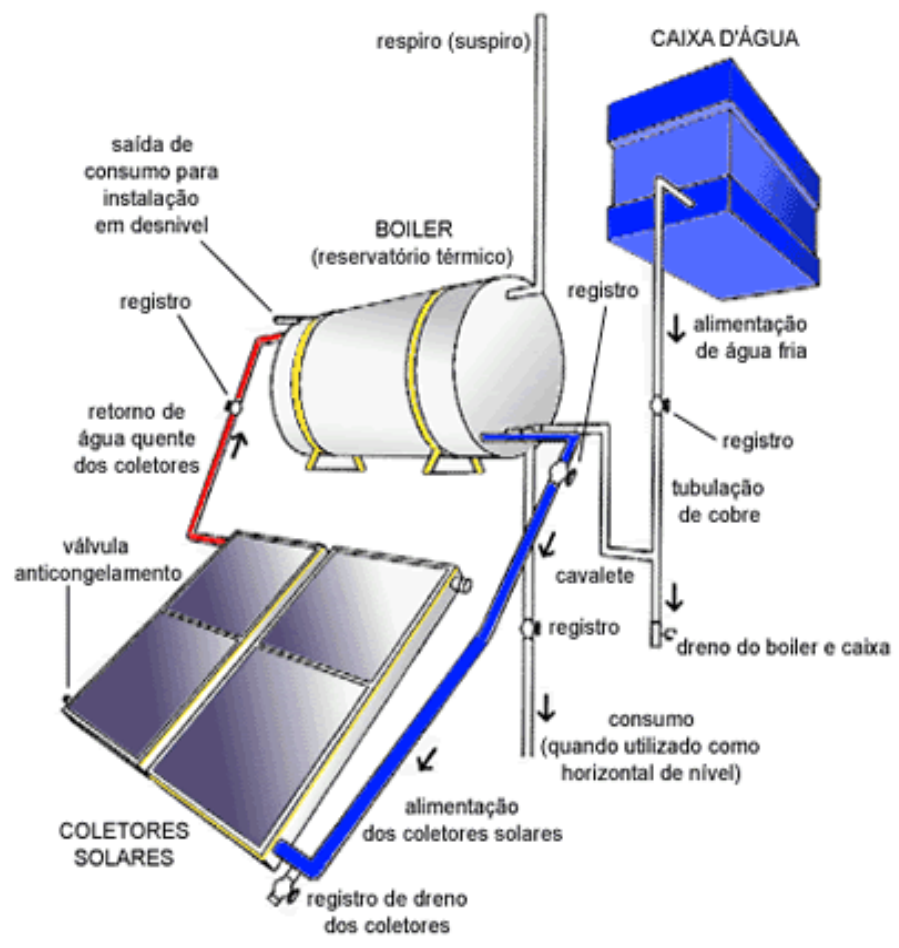

FIGURA 1. Diagrama de um sistema fototérmico típico. Diagram of a typical solar thermal system.

Para aumentar a eficiência dos sistemas fototérmicos, pode-se fazer uso de concentradores solares. Estes equipamentos interceptam os raios solares e refletem-nos na placa coletora, aumentando assim a radiação solar captada pelo sistema. A tecnologia de concentradores solares já tem sido explorada para algumas aplicações, como desinfecção biológica de águas em comunidades isoladas (PATERNIANI \& SILVA, 2005).

No Brasil, muitas unidades produtoras de leite utilizam aquecedores elétricos para suprir a necessidade de água quente. Nesses casos, o aquecimento de água pode representar até $27 \%$ do consumo de energia elétrica da unidade (BALDASSIN JÚNIOR et al., 2006). Desse modo, outras tecnologias vêm sendo exploradas para diminuir os custos de produção, como aquecedores a gás e a energia solar. Neste trabalho, analisou-se a viabilidade do uso de concentradores de radiação solar em sistemas fototérmicos para higienização de salas de ordenha. 


\section{MATERIAL E MÉTODOS}

O estudo referente a este trabalho foi conduzido nos Laboratórios de Energia na Agricultura do Departamento de Engenharia Agrícola, da Universidade Federal de Viçosa, município de Viçosa, Minas Gerais. A cidade possui altitude de $648,74 \mathrm{~m}$, latitude de $20^{\circ} 45^{\prime} 14^{\prime \prime}$ ao sul e longitude de $42^{\circ} 52^{\prime} 53^{\prime \prime}$ a oeste de Greenwich.

Para realizar o dimensionamento e a análise econômica do sistema fototérmico, utilizou-se o software RETScreen de análise de projetos de energia limpa, programa computacional desenvolvido por universidades e empresas do Canadá. Este software é fornecido sem custos pelo Natural Resources Canada e pode ser usado para avaliar a produção e a economia de energia, os custos durante o tempo de vida, a redução das emissões de poluentes e a análise financeira e de risco para vários tipos de tecnologias renováveis (RETSCREEN, 2009).

Na simulação realizada, foi considerado que os coletores solares, com e sem concentradores, são orientados na posição leste-oeste com correção de $21^{\circ}$ de azimute devido à declinação magnética da Terra. Além disso, com essa orientação, os concentradores não obstruem a incidência dos raios solares com a mudança de posição do Sol ao longo do dia. Os concentradores são acoplados de modo a maximizar a radiação que atinge a placa coletora, e isso ocorre quando o ângulo de reflexão da radiação no concentrador é de 30 (PALZ, 1981). Na Figura 2, é evidenciada a configuração do coletor solar com concentradores, em corte transversal (a) e vista superior (b).

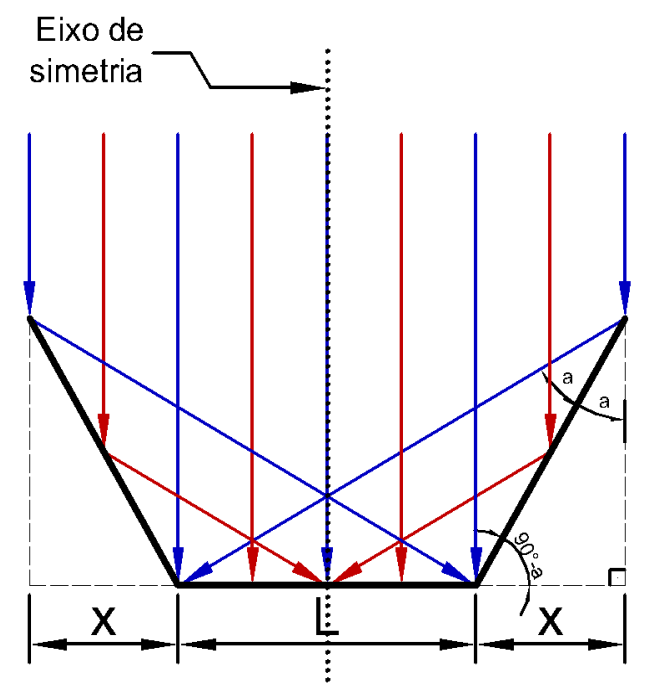

(a)

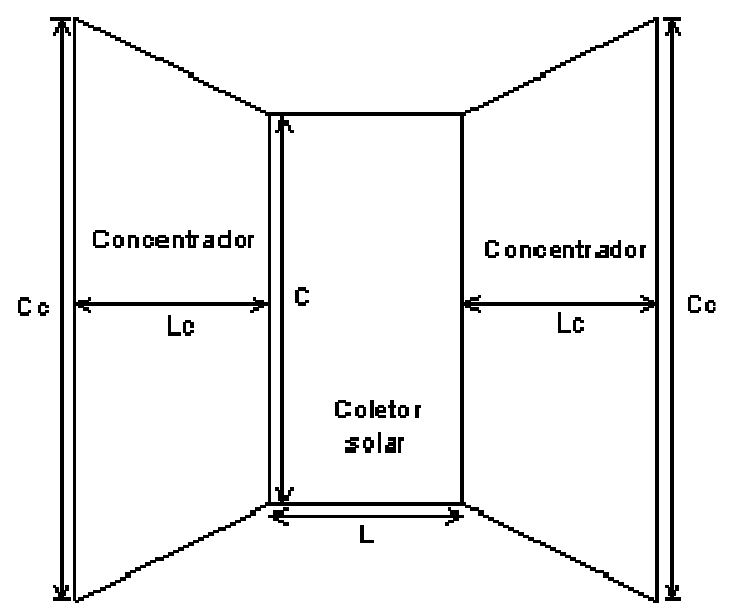

(b)

FIGURA 2. Coletor solar com concentrador: a) vista em corte transversal; b) vista superior. Solar collector with concentrator: a) cross section view, b) top view.

O valor da largura adicional do coletor é calculado utilizando a eq.(1):

$$
\mathrm{x}=\mathrm{L} \frac{\tan (\mathrm{a})}{\tan (2 \mathrm{a})-\tan (\mathrm{a})}
$$

em que,

$\mathrm{x}$ - largura adicional ao coletor solar, $\mathrm{m}$;

a - ângulo de reflexão da radiação no concentrador, graus, e

$\mathrm{L}$ - largura do coletor, $\mathrm{m}$.

A largura do concentrador (Lc) é dada pela eq.(2):

$$
\mathrm{Lc}=\frac{\mathrm{x}}{\operatorname{sen}(\mathrm{a})}
$$


O comprimento da parte externa do concentrador $(\mathrm{Cc})$ é dado pelo comprimento do coletor solar mais $50 \%$ do mesmo para cada lado do coletor, ou seja, o comprimento externo do concentrador é igual ao dobro do comprimento do coletor. Sendo que, em sistemas fototérmicos com concentradores planos de alumínio anodizado especular, com 86\% de refletância, podem-se substituir $30 \%$ da área de coletores por concentradores para manter a mesma fração solar (VOROBIEFF, 2008).

$\mathrm{Na}$ análise econômica, foi considerado o caso-base de um pequeno produtor de leite tipo $\mathrm{B}$ do município de Viçosa - MG, com um rebanho de 30 vacas em lactação e produção de 10 litros de leite/vaca/dia. Segundo a Normativa $\mathrm{n}^{\mathrm{o}}$ 51, de 14 de agosto de 2002 do MAPA, para higienização de equipamentos de ordenha tipo B, são necessários 100 litros de água por animal, mais 6 litros de água por litro de leite produzido (BRASIL, 2002). E para garantir uma desinfecção efetiva, a água deve estar com temperatura mínima de $71{ }^{\circ} \mathrm{C}$ (RENTERO, 2000). Portanto, o produtor tem uma demanda diária de 4.800 litros de água a $71{ }^{\circ} \mathrm{C}$ para a higienização da sala de ordenha.

Foram analisadas três opções para aquecimento de água com reservatório de acumulação: sistema com resistência elétrica, sistema solar com concentrador e sistema solar sem concentrador. Para o caso-base, o sistema fototérmico é suplementado por fornalha a lenha com trocador de calor, utilizando-se como biomassa de eucalipto comprado. Analisaram-se o custo total destas alternativas e o valor presente líquido (VPL) do sistema solar suplementado por lenha comprada, lenha produzida na propriedade rural, energia elétrica e gás liquefeito de petróleo (GLP), e o VPL foi calculado usando como caso de referência aquecimento de água por aquecedor elétrico.

No dimensionamento do caso-base, foi considerado um horizonte de planejamento de 20 anos para a vida útil do sistema fototérmico, $\mathrm{R} \$ 50,00$ por ano para a manutenção do sistema solar referente à limpeza dos componentes, taxa de juros de $12 \%$ ao ano, custo da energia elétrica igual a $\mathrm{R} \$ 0,57 \mathrm{kWh}^{-1}$, inflação de $6 \%$ ao ano e aumento na energia elétrica acima da inflação de $1,5 \%$ ao ano. Considerou-se, ainda, nulo o subsídio na compra dos componentes do sistema fototérmico (coletores, reservatório e concentradores, quando presentes no sistema). E adotou-se custo de instalação, incluindo as conexões, igual a $20 \%$ do valor dos componentes do sistema solar térmico.

Cada coletor solar de $2 \mathrm{~m}^{2}$ custa $\mathrm{R} \$ 600,00$, e um reservatório térmico de 5.000 litros custa $\mathrm{R} \$ 12.000,00$ no mercado local, sendo este o imediatamente superior que atende à demanda diária de 4.800 litros de água quente. O concentrador considerado, de alumínio anodizado especular com $86 \%$ de refletância, custa $\mathrm{R} \$ 25,50$ o metro quadrado a placa com espessura de $0,3 \mathrm{~mm}$. O investimento para a construção da fornalha, mais o trocador de calor foram estimados em $\mathrm{R} \$ 2.000,00$. A lenha de eucalipto custa no mercado regional $\mathrm{R} \$ 50,00$ o metro cúbico, enquanto a lenha de eucalipto produzido na propriedade rural tem custo de $\mathrm{R} \$ 25,00$ o metro cúbico. Já um botijão de $13 \mathrm{~kg}$ de GLP custa R \$ 40,00.

$\mathrm{Na}$ análise de sensibilidade do sistema fototérmico, com e sem concentradores, o valor presente líquido destas alternativas foi calculado, novamente, usando como caso de referência aquecedor elétrico. Os parâmetros considerados e a variação destes estão apresentados na Tabela 1.

Os diferentes sistemas de aquecimento de água para higienização de salas de ordenha foram comparados com o sistema tradicional de aquecimento de água utilizando reservatório, que no estudo foi considerado como tendo a capacidade de 5.000 litros para a demanda diária de 4.800 litros $\mathrm{dia}^{-1}$. 
TABELA 1. Parâmetros de entradas para a análise de sensibilidade do sistema fototérmico. Input parameters for the sensibility analysis of the solar thermal system.

\begin{tabular}{|c|c|c|c|c|c|c|c|}
\hline \multirow{2}{*}{$\begin{array}{c}\text { Parâmetros } \\
\text { Número de vacas lactantes }\end{array}$} & \multicolumn{7}{|c|}{ Variação dos Parâmetros } \\
\hline & 20 & 24 & 27 & $30^{*}$ & 33 & 36 & 40 \\
\hline Custo da energia $\left(\mathrm{R} \$ \mathrm{kWh}^{-1}\right)$ & 0,46 & 0,51 & 0,54 & $0,57 *$ & 0,60 & 0,63 & 0,68 \\
\hline Custo da lenha $\left(\mathrm{R} \$ \mathrm{~m}^{-3}\right)$ & 40 & 45 & 47,5 & $50 *$ & 52,5 & 55 & 60 \\
\hline Taxa de juros (\% a.a. $\left.{ }^{-1}\right)$ & 6 & 8 & 10 & $12^{*}$ & 14 & 16 & 18 \\
\hline Custo dos coletores $\left(\mathrm{R} \$ \mathrm{~m}^{-2}\right)$ & 240 & 270 & 285 & $300 *$ & 315 & 330 & 360 \\
\hline Custo do reservatório $\left(\mathrm{R} \$ \mathrm{~L}^{-1}\right)$ & 1,92 & 2,16 & 2,28 & $2,40 *$ & 2,52 & 2,64 & 2,88 \\
\hline Custo dos concentradores $\left(\mathrm{R} \$ \mathrm{~m}^{-2}\right)$ & 20,4 & 23,0 & 24,2 & $25,5^{*}$ & 26,8 & 28,1 & 30,6 \\
\hline Vida útil do sistema (anos) & 10 & 13 & 16 & $20 *$ & 23 & 26 & 30 \\
\hline Subsídio no capital inicial $(\%)$ & $0 *$ & 10 & 20 & 30 & 40 & 50 & - \\
\hline
\end{tabular}

*aso-base

\section{RESULTADOS E DISCUSSÃO}

Para o caso-base proposto, demanda diária de 4.800 litros de água a $71{ }^{\circ} \mathrm{C}$, o dimensionamento do sistema fototérmico, sem concentradores, exigiu 47 coletores de $2 \mathrm{~m}^{2}$, enquanto o sistema fototérmico, com concentradores, exigiu 33 coletores de $2 \mathrm{~m}^{2}$ e $165 \mathrm{~m}^{2}$ de concentradores. O custo total, em valor presente, das alternativas de aquecimento consideradas para o caso-base, em 20 anos de uso é apresentado na Tabela 2.

TABELA 2. Custo total na vida útil, em valores presentes, das alternativas de aquecimento de água para o caso-base. Life cost, in present values, for the alternatives for water heating for the base case.

\begin{tabular}{lcccc}
\hline & Custo inicial (R\$) & $\begin{array}{c}\text { Manutenção } \\
(\mathrm{R} \$)\end{array}$ & $\begin{array}{c}\text { Energia Elétrica ou } \\
\text { Biomassa }(\mathrm{R} \$)\end{array}$ & Custo Total (R\$) \\
\hline $\begin{array}{l}\text { Aquecedor elétrico } \\
\text { por acumulação }\end{array}$ & $14.400,00$ & - & $323.136,00$ & $337.536,00$ \\
$\begin{array}{l}\text { Sistema solar sem } \\
\text { concentrador }\end{array}$ & $50.240,00$ & $1.000,00$ & $32.400,00$ & $83.640,00$ \\
$\begin{array}{l}\text { Sistema solar com } \\
\text { concentrador }\end{array}$ & $45.209,00$ & $1.000,00$ & $32.400,00$ & $78.609,00$ \\
\hline
\end{tabular}

- O sistema fototérmico com concentrador foi a opção de aquecimento que apresentou menor custo total, configurando, desse modo, a opção mais atrativa.

- O uso de concentradores planos proporciona uma redução de cerca de $10 \%$ no custo inicial do sistema solar, causando um decréscimo de cerca de $6 \%$ no custo total do sistema fototérmico.

- O elevado custo com energia elétrica foi responsável pela discrepância do custo total do uso de aquecedor elétrico e sistema fototérmico, sendo o custo total do primeiro cerca de quatro vezes maior do que os demais.

O valor presente líquido do sistema fototérmico suplementado por lenha de eucalipto comprada, lenha de eucalipto produzida na propriedade, energia elétrica ou GLP está apresentado na Figura 3. 
$\operatorname{VPL}(\mathrm{R} \$)$

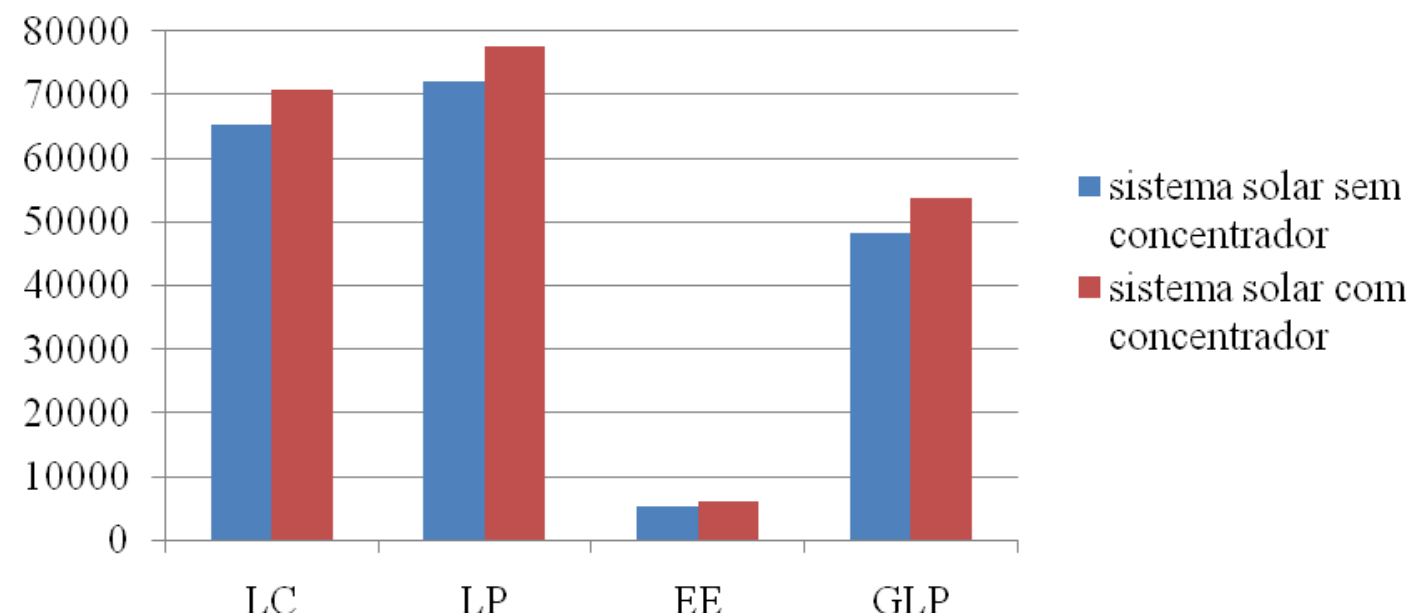

FIGURA 3. Valores presentes líquidos do sistema fototérmico suplementado por lenha de eucalipto comprada (LC), lenha de eucalipto produzida na propriedade (LP), energia elétrica (EE) ou GLP. Net present value of the solar thermal system supplemented by eucalyptus wood purchased (LC), Eucalyptus wood produced on the property (LP), electricity (EE) or LPG.

Conforme o gráfico anterior, o sistema fototérmico suplementado por lenha produzida na propriedade tem maior valor presente líquido; portanto, entre as opções de energia suplementar analisadas, é a mais atrativa financeiramente, sendo que o sistema suplementado por energia elétrica foi a configuração que apresentou menor VLP, com valor de um doze avos da melhor opção de aquecimento. E o VPL do sistema solar, com concentrador, foi em média $10 \%$ maior que o do sistema sem concentrador.

A partir da variação dos parâmetros considerados, realizou-se a análise de sensibilidade do sistema fototérmico com e sem concentradores, tendo como referência o uso de aquecedor elétrico. O comportamento do VPL em função de cada parâmetro é apresentado nas Figuras de 4 a 11.

Nas Figuras 4 e 5, apresentam-se as variações do valor presente líquido do sistema fototérmico em razão do número de vacas lactantes e do custo da energia elétrica.

VPL $(\mathrm{R} \$)$

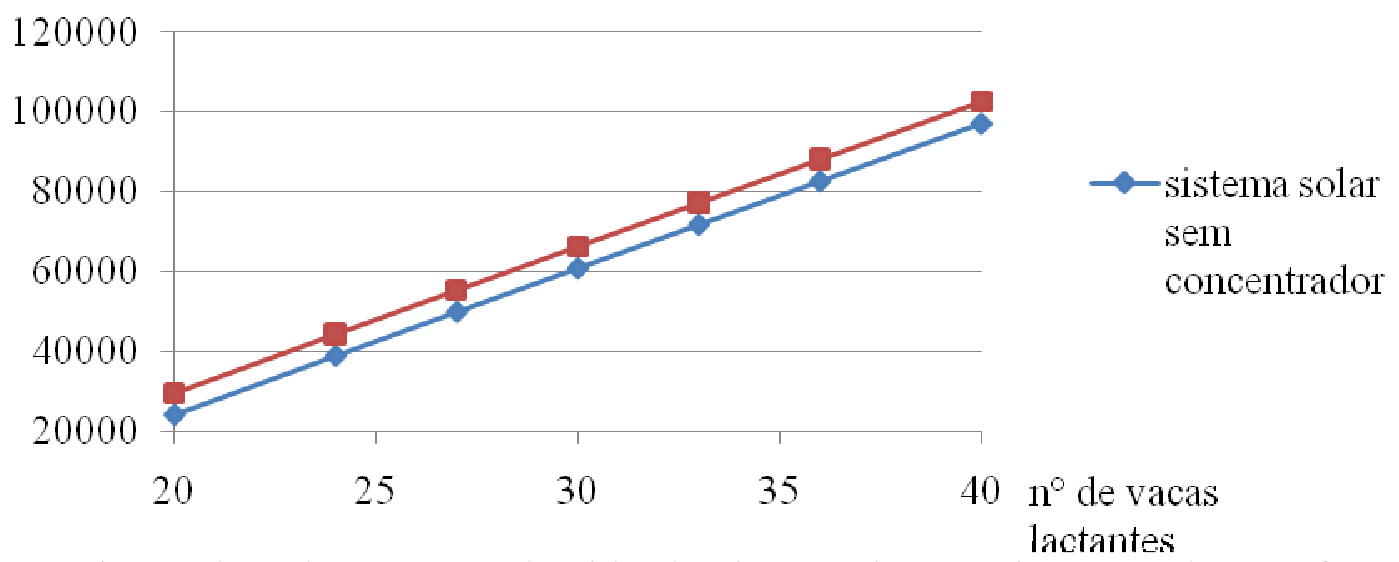

FIGURA 4. Variação do valor presente líquido do sistema de aquecimento solar em função do número de vacas lactantes. Net present value variation of the thermal solar system as a function of the number of lactating cows.

Percebe-se que o valor presente líquido do sistema fototérmico apresentou acréscimo com o aumento do número de vacas lactantes, devendo-se isso ao maior aproveitamento do equipamento 
solar adquirido, sendo a variação total do VPL de aproximadamente $277 \%$. E o sistema com concentradores proporcionou maior VPL por apresentar menor valor de capital inicial.

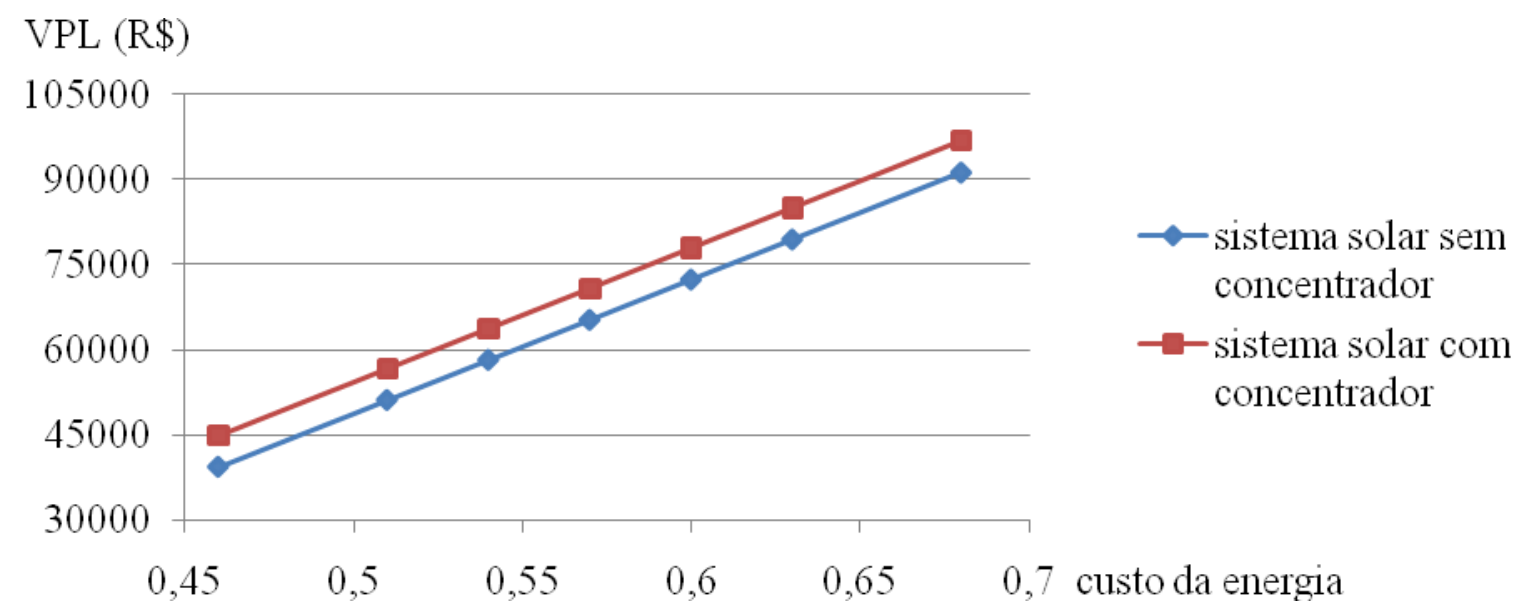

FIGURA 5. Variação do valor presente líquido do sistema de aquecimento solar em função do custo da energia elétrica. Net present value variation of the solar thermal system as a function of the electricity costs.

Houve acréscimo no valor presente líquido do sistema fototérmico com o aumento do custo da energia elétrica. Desta forma, maior o valor da energia elétrica, mais lucrativo é o uso de energia solar para aquecimento de água, sendo que o sistema com concentradores apresentou maior VPL devido ao menor valor de capital inicial.

Nas Figuras 6 e 7, apresentam-se as variações do valor presente líquido do sistema fototérmico em razão do custo da lenha de eucalipto comprada e da taxa de juros.

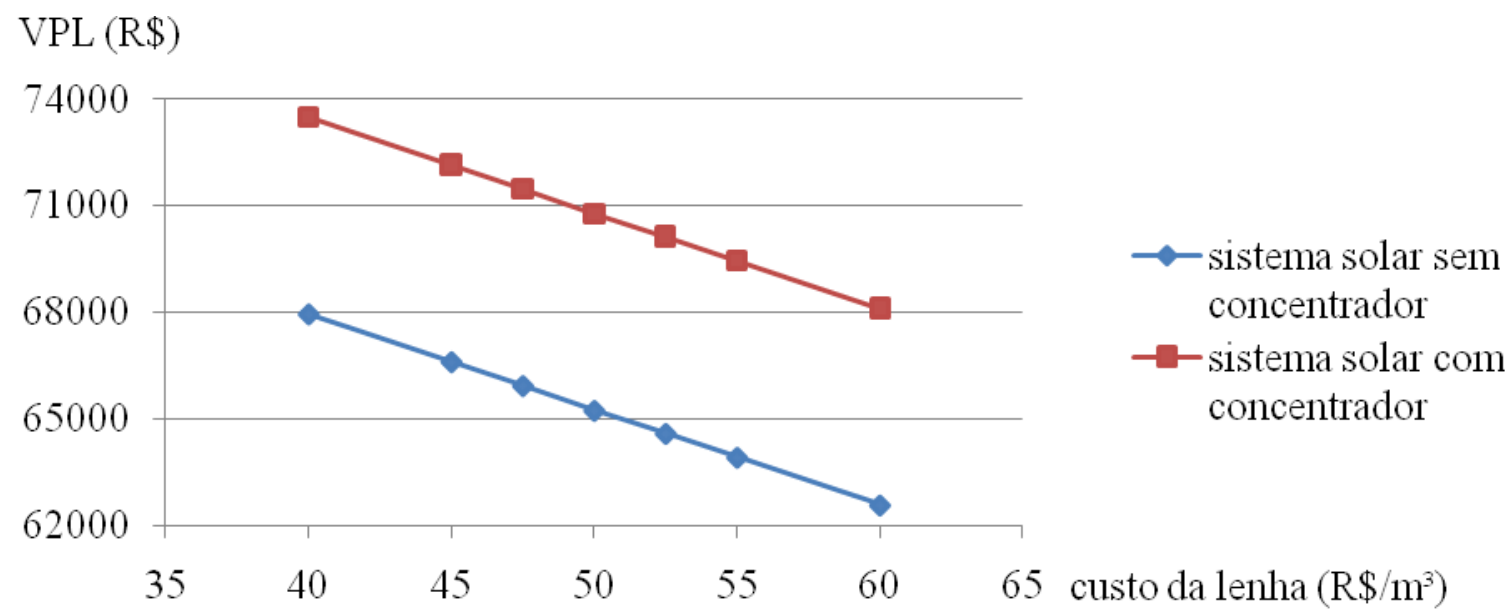

FIGURA 6. Variação do valor presente líquido do sistema de aquecimento solar em função do custo da lenha de eucalipto comprada. Net present value variation of the thermal solar system as a function of the cost of eucalyptus wood purchased.

Observa-se que o valor presente líquido do sistema fototérmico apresentou decréscimo com o aumento do custo da lenha de eucalipto comprada, pois maior será o custo com energia auxiliar para atender à demanda de água quente, sendo a variação total do VPL cerca de 5\%. E novamente o sistema com concentradores proporcionou maior VPL por apresentar menor valor de capital inicial. 


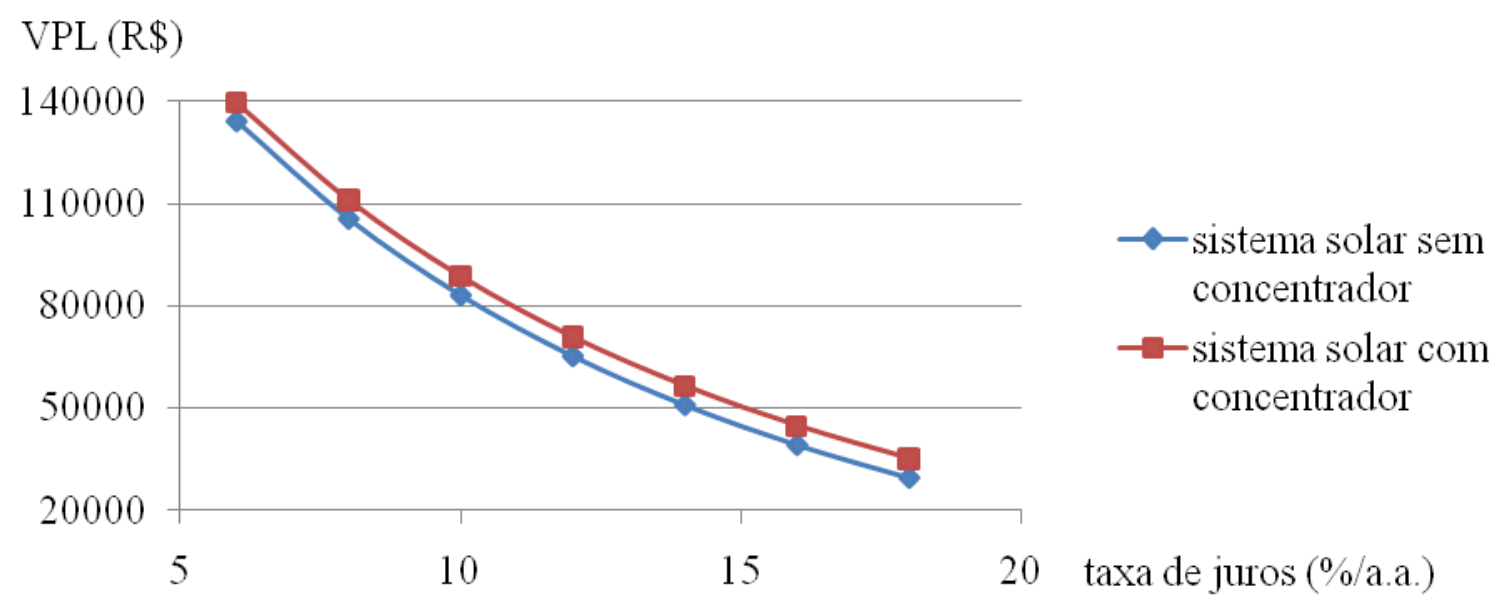

FIGURA 7. Variação do valor presente líquido do sistema de aquecimento solar em função da taxa de juros anual. Net present value variation of the thermal solar system as a function of the annual interest rate.

Houve decréscimo no valor presente líquido do sistema fototérmico com o aumento da taxa de juros, porque o capital investido no sistema solar poderia ser aplicado em um investimento mais rentável, sendo que o sistema com concentradores apresentou maior VPL por possuir menor valor de capital inicial.

Nas Figuras 8; 9 e 10, apresentam-se as variações do valor presente líquido do sistema fototérmico em razão do custo dos coletores, do reservatório e dos concentradores.

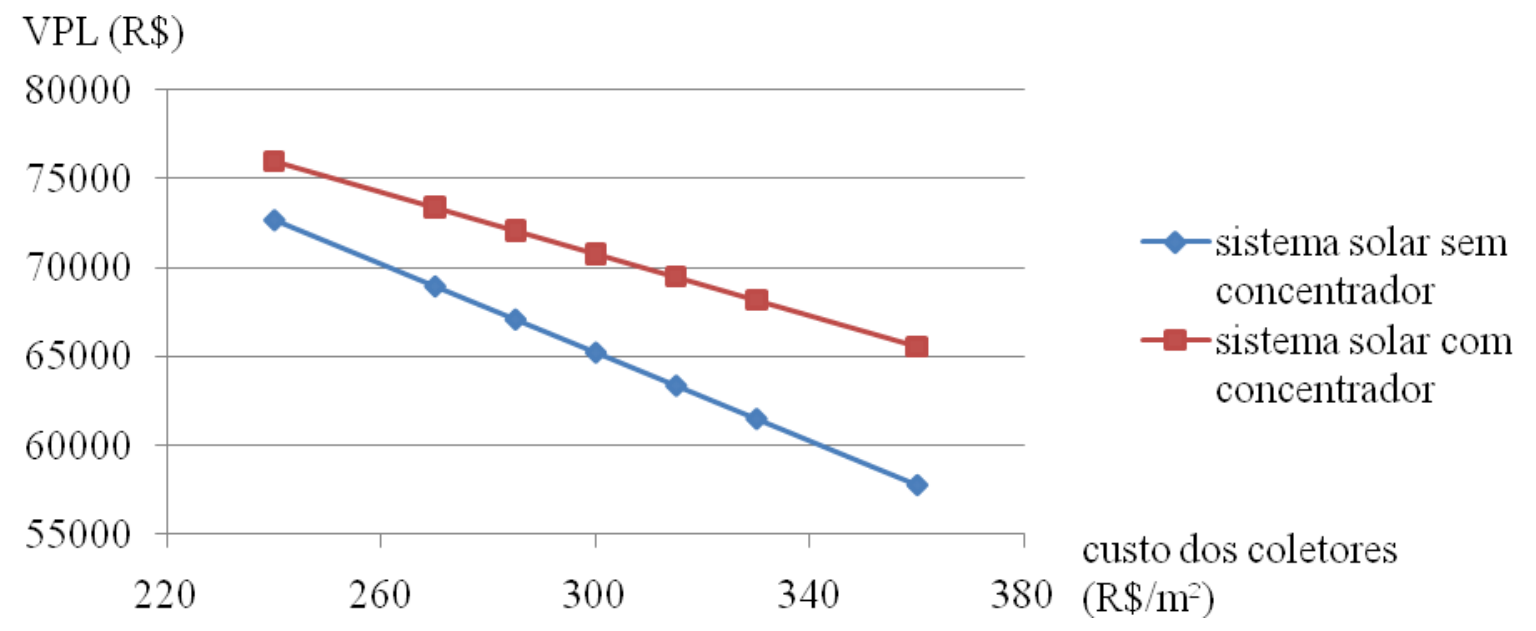

FIGURA 8. Variação do valor presente líquido do sistema de aquecimento solar em função do custo dos coletores. Net present value variation of thermal solar system as a function of the cost of the collectors.

Verifica-se que o valor presente líquido do sistema fototérmico apresentou decréscimo com aumento do custo dos coletores, devido ao maior preço do sistema solar. Todavia, o decréscimo do VPL foi mais expressivo no sistema sem concentradores, pois este possui mais coletores em sua configuração, apresentando o sistema com concentradores maior VPL devido ao menor valor de capital inicial. 


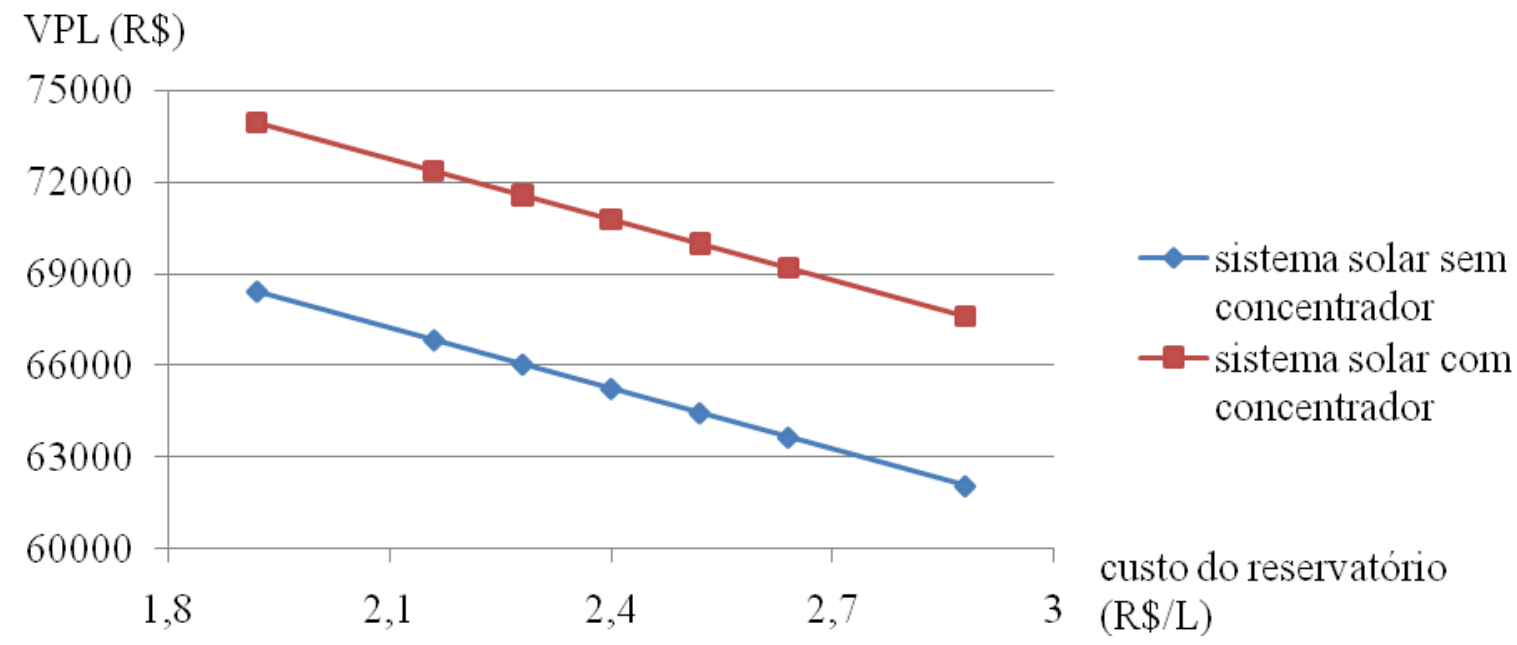

FIGURA 9. Variação do valor presente líquido do sistema de aquecimento solar em função do custo do reservatório de água quente. Net present value variation of the thermal solar system as a function of the cost of the heated water tank accumulation.

Houve decréscimo no valor presente líquido do sistema fototérmico com o aumento do custo do reservatório, devido ao maior preço do sistema solar, sendo a variação total do VPL em torno de $10 \%$. E novamente o sistema com concentradores proporcionou maior VPL por apresentar menor valor de capital inicial.

VPL (R\$)

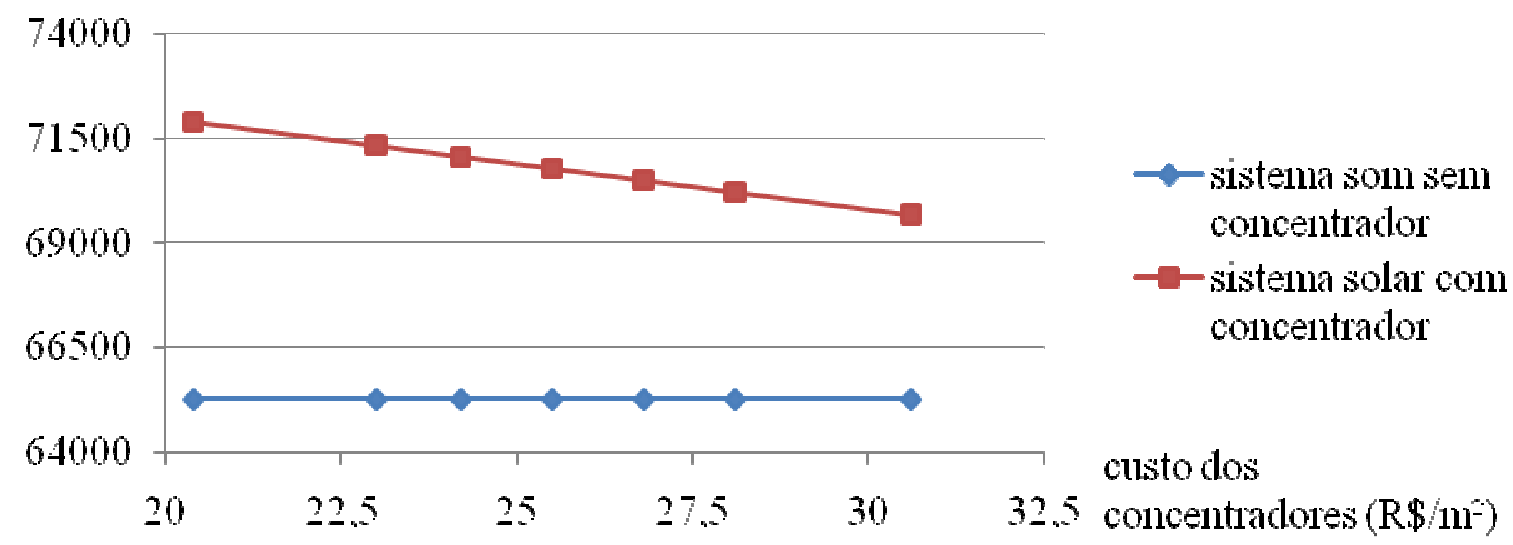

FIGURA 10. Variação do valor presente líquido do sistema de aquecimento solar em função do custo dos concentradores. Net present value variation of the thermal solar system as a function of the concentrator costs.

O valor presente líquido do sistema fototérmico, com concentrador, apresentou decréscimo com o aumento do custo deste equipamento, devido ao maior preço do sistema solar, enquanto o sistema sem concentradores se manteve constante por não depender dessa variável. E o sistema com concentradores apresentou maior VPL devido ao menor valor de capital inicial.

Nas Figuras 11 e 12, apresentam-se as variações do valor presente líquido do sistema fototérmico em razão da vida útil do sistema e do subsídio no capital inicial. 


\section{VPL $(\mathrm{R} \$)$}

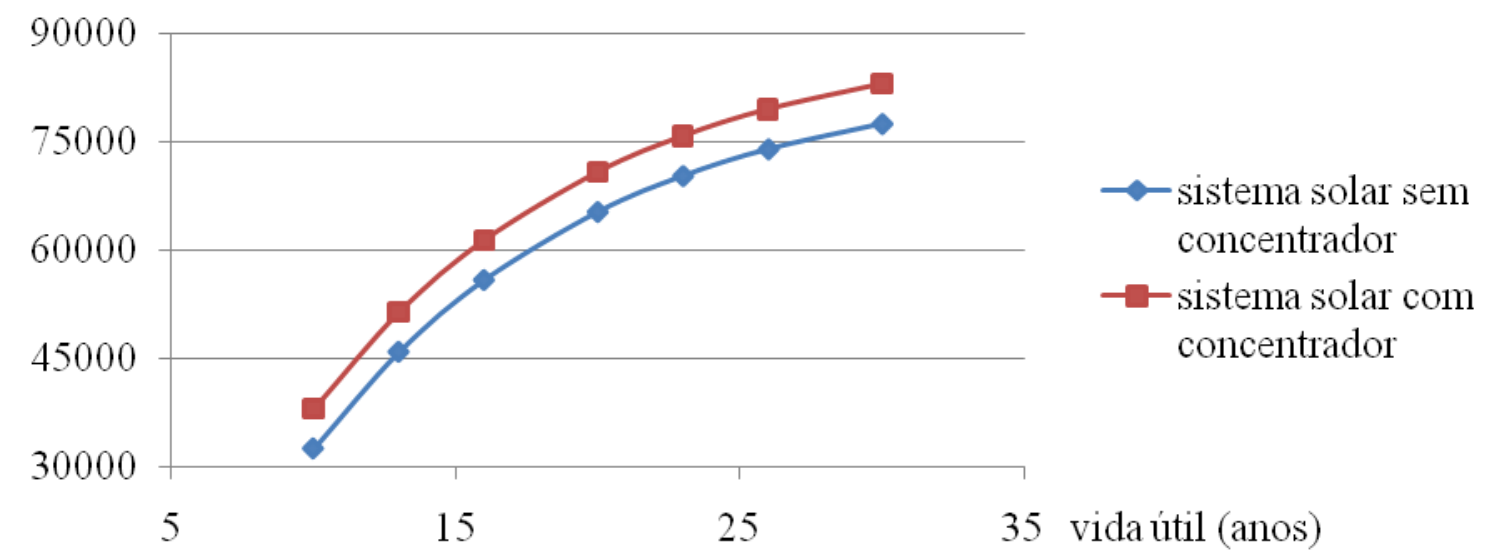

FIGURA 11. Variação do valor presente líquido do sistema de aquecimento solar em função da vida útil do sistema. Net present value variation of the thermal solar system as a function of the system expectancy of life.

Nota-se que houve acréscimo no valor presente líquido do sistema fototérmico com o aumento da vida útil do mesmo, pois gera economia com energia elétrica por um prazo maior, sendo a variação total do VPL de aproximadamente $128 \%$, e o sistema com concentradores proporcionou maior VPL por apresentar menor valor de capital inicial.

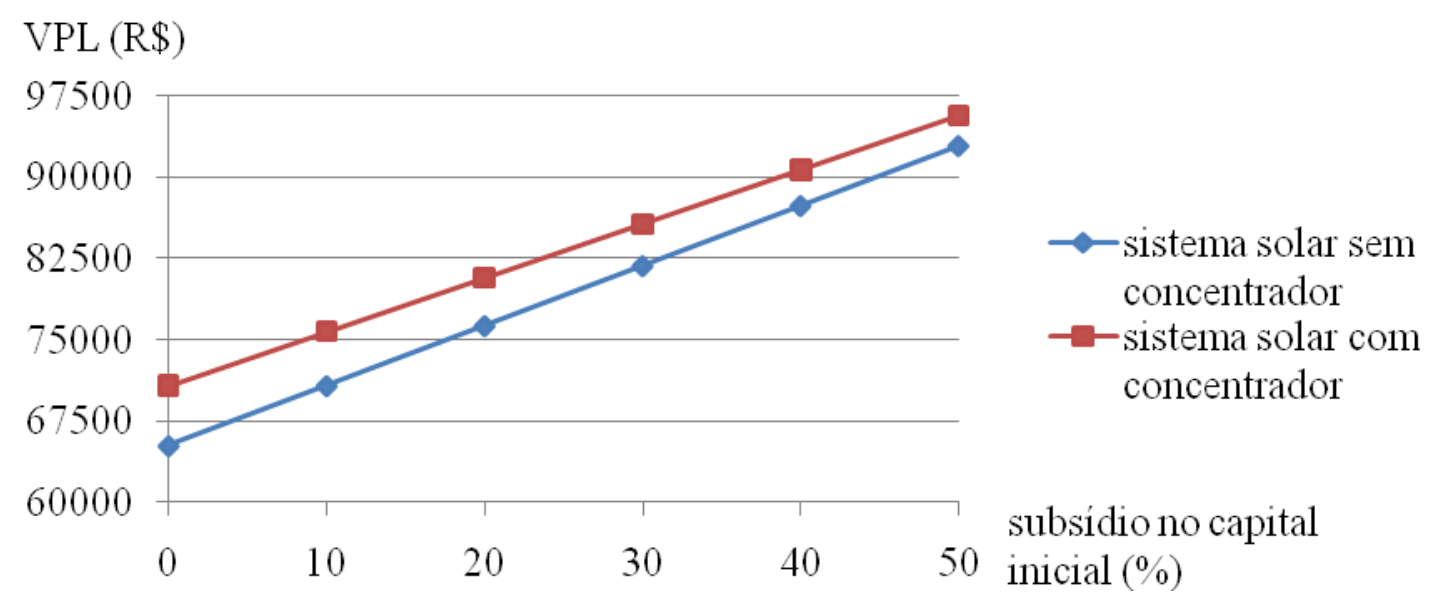

FIGURA 12. Variação do valor presente líquido do sistema de aquecimento solar em função do subsídio no capital inicial. Net present value variation of the thermal solar system as a function of the capital initial subsidy.

Pode ser observado que o valor presente líquido do sistema fototérmico apresentou acréscimo com o aumento do subsídio no capital inicial, devido ao menor custo para a aquisição dos equipamentos (coletores, reservatórios e concentradores, quando presentes). E novamente o sistema com concentradores apresentou maior VPL por possuir menor valor de capital inicial.

Verificou-se que os parâmetros que mais modificaram o valor presente líquido do sistema fototérmico foram a taxa de juros, o número de vacas lactantes e a vida útil do sistema, respectivamente, enquanto o custo dos concentradores, o custo da lenha de eucalipto comprada e o custo do reservatório foram as variáveis que menos alteraram o VPL do sistema solar, nesta ordem. A variação média total do VPL dos parâmetros analisados foi de $14 \%$, e o VPL do sistema com concentradores foi cerca de $10 \%$ maior que o do sistema sem concentradores. Além disso, percebeu-se que apenas a taxa de juros e a vida útil do sistema variaram de forma exponencial, enquanto os demais parâmetros apresentaram variação linear. 


\section{CONCLUSÕES}

Entre as alternativas de aquecimento de água analisadas, o sistema fototérmico com concentrador foi a opção mais viável financeiramente, seguida do sistema fototérmico sem concentrador e aquecedor elétrico.

O uso de concentradores planos proporcionou a redução de $10 \%$ no custo de aquisição do sistema solar e o decréscimo de $6 \%$ no custo total do sistema fototérmico na sua vida útil.

A ordem decrescente de maior viabilidade econômica de fonte de energia auxiliar para aquecimento de água foi: lenha de eucalipto produzida na propriedade rural, lenha de eucalipto comprada, gás liquefeito de petróleo e energia elétrica.

Os parâmetros que mais modificaram o valor presente líquido do sistema fototérmico foram a taxa de juros, o número de vacas lactantes e a vida útil do sistema, nesta ordem.

\section{AGRADECIMENTOS}

À Coordenadoria de Apoio ao Pessoal de Ensino Superior (CAPES), ao Conselho Nacional de Desenvolvimento Científico e Tecnológico (CNPq) e à Fundação de Amparo à Pesquisa do Estado de Minas Gerais (FAPEMIG).

\section{REFERÊNCIAS}

AMARAL, L.A.; ISA H.; DIAS, L.T.; ROSSI, O.D.; FILHO, A.N. Avaliação da eficiência da desinfecção de teteiras e dos tetos no processo de ordenha mecânica de vacas. Pesquisa Veterinária Brasileira, Rio de Janeiro, v.24, n.4, p.173-177, 2004.

BALDASSIN JÚNIOR, R.; CORTEZ, L.A.B.; JORDAN, R.A.; NEVES FILHO, L.C.; SILVEIRA JÚNIOR, V.; FERREIRA, T.A.B. Bombas de calor em propriedades leiteiras. In: CONGRESSO INTERNACIONAL SOBRE GERAÇÃO DISTRIBUÍDA E ENERGIA NO MEIO RURAL, 6 ., 2006, Campinas. Disponível em: < http://www.proceedings.scielo.br/scielo .php?pid= MSC0000000022006000100030\&script=sci_arttext >. Acesso em: 18 maio 2010.

BOTEGA, J.V.L.; BRAGA JÚNIOR, R.A.; LOPES, M.A.; RABELO, G.F. Diagnóstico da automação na produção leiteira. Ciência e Agrotecnologia, Lavras, v.32, n.2, p.635-639, 2008.

BRASIL. Ministério da Agricultura, Pecuária e Abastecimento. Instrução Normativa no ${ }^{51}$, de 20 de setembro de 2002. Diário Oficial da União, Brasília, 18 de setembro de 2002. Seção 1.

DAMASIO, F.; STEFFANI, M.H. Ensinando física com consciência ecológica e com materiais descartáveis. Revista Brasileira de Ensino de Física, São Paulo, v.29, n.4, 2007. Disponível em: $<$ http://www.scielo.br/scielo.php?pid=S0102-47442007000400018\&script=sci_arttext>. Acesso em: 4 nov. 2009.

GUERREIRO, P.K.; MACHADO, M.R.F.; BRAGA, G.C.; GASPARINO E.; FRANZENER, A. da S.M. Qualidade microbiológica de leite em função de técnicas profiláticas no manejo de produção. Ciência e Agrotecnologia, Lavras, v.29, n.1, p.216-222, 2005.

MARINI, J.A.; ROSSI, L.A. Sistematização do dimensionamento técnico e econômico de sistemas fotovoltaicos isolados por meio de programa computacional. Engenharia Agrícola, Jaboticabal, v.25, n.1, p.67-75, 2005.

NERO L.A.; VIÇOSA, G.N.; PEREIRA, F.E.V. Qualidade microbiológica do leite determinada por características de produção. Ciência e Tecnologia de Alimentos, Campinas, v.29, n.2, p.386-390, 2009.

OLIVEIRA, L.F.C. de; FERREIRA, R. de C.; ALMEIDA, R. de A.; LOBATO, E.J.V.; MEDEIROS, A.M. de M. Potencial de redução do consumo de energia elétrica pela utilização de 
aquecedores solares no Estado de Goiás. Engenharia Agrícola, Jaboticabal, v.28, n.3, p.406-416, 2008.

PALZ, W. Energia solar e fontes alternativas. São Paulo: Hemus Livraria Editora, 1981. 358 p.

PATERNIANI, J.E.S.; SILVA, M.J.M. da. Desinfecção de efluentes com tratamento terciário utilizando energia solar: avaliação do uso do dispositivo para concentração dos raios solares. Engenharia Sanitária e Ambiental, Rio de Janeiro, v.10, n.1, p.9-13, 2005.

RENTERO, N. Como fazer a limpeza de equipamentos de ordenha. Revista Balde Branco, São Paulo, v.1, n.426, 2000. Disponível em:

$<$ http://sincal.org.br/portal/index.php?option=com_content $\&$ view=article \&id=22:como-fazer-alimpeza-de-equipamentos-de-ordenha\&catid=22:leite-artigos \&Itemid=39>. Acesso em: 19 nov. 2009.

RETSCREEN. RETscreen análise de projetos de energia limpa. Disponível em: <http://www. retscreen.net/pt/home.php>. Acesso em: 4 abr. 2009.

SOUZA, G.N.; BRITO, J.R.F.; MOREIRA, E.C.; BRITO, M.A.V.P.; BASTOS, R.R. Fatores de risco associados à alta contagem de células somáticas do leite do tanque em rebanhos leiteiros da Zona da Mata de Minas Gerais. Arquivo Brasileiro de Medicina Veterinária e Zootecnia, Belo Horizonte, v.57, supl.2, p.251-260, 2005.

VOROBIEFF, C.L. Concentradores solares planos em sistemas fototérmicos. 2008. $79 \mathrm{f}$. Dissertação (Mestrado em Engenharia Agrícola) - Universidade Federal de Viçosa, Viçosa - MG, 2008. 